\title{
Dasein y auto-apropiación: el tiempo como constitutivo de nuestra realidad
}

Recibido: febrero 2 de 2015 | Aceptado: junio 15 de 2017

DOI: 10.17230/co-herencia.15.29.4

Felipe Johnson Muñoz*
felipe.johnson@ufrontera.cl

Resumen Este artículo se propone exponer el fenómeno del existir humano, denominado por Heidegger "Dasein", en íntima relación con el problema de la constitución de la realidad. Para ello, se entenderá lo real como aquella multiplicidad de entes con los que la vida se confronta diariamente. En este sentido, se plantea que esta multiplicidad no pertenece a lo percibido, sino que deviene más bien de la estructura de la percepción sensible. Mediante advertencias de Heidegger en torno a la filosofía kantiana y a través del uso de ejemplos propios, se realzarán los momentos trascendentales de la sensibilidad: el espacio y el tiempo, hasta llegar al cuidado (Sorge) como ser del Dasein. Así, comprendiendo al cuidado en su sentido temporal, advertiremos que lo real se origina desde el futuro perteneciente al existir mismo. Con lo anterior, el estudio expondrá cómo es que el "Dasein" puede ser entendido como aperturidad (Erschlossenheit) o de-velamiento de nuestra realidad.

\section{Palabras clave:}

Cuidado, temporalidad, Dasein, fenomenología, Heidegger.

\section{Dasein and self-appropriation: time as a constituent of our reality}

\begin{abstract}
This paper aims to discuss the phenomenon of human existence, which Heidegger called 'Dasein', in close connection with the problem of the constitution of reality. For this purpose, the real is construed as a multiplicity of entities daily life has to deal with. In this regard, the paper suggests that this multiplicity does not pertain to the perceived as such, but rather results from the structure of sense-perception. Based on Heidegger's references to Kantian philosophy and through own examples, the paper will highlight the transcendental moments of sensibility: space and time, up until its last deployment stage, care (Sorge), as Dasein's Being. Thus, by understanding care in its temporal sense, the paper will state that the real as such originates in the future that pertains to existence itself. Based on the above, this study will assert that 'Dasein' can be considered as disclosedness (Erschlossenheit) or un-concealment of our reality.
\end{abstract}

\section{Keywords:}

Care, temporality, Dasein, phenomenology, Heidegger.
Este trabajo pertenece al Proyecto de Investigación DIUFRO-DI 140055: "La presentación futura del Ahí: la fundación temporal del Existir en Heidegger".

** Doctor en Filosofía por la Albert-LudwigUniversität (Freiburg/ Alemania). Académico del Departamento de Ciencias Sociales de la Universidad de La Frontera, TemucoChile. ORCID ID: 0000 0001-6063-9322 


\section{El Dasein y el problema de la constitución del mundo}

Sin duda, uno de los conceptos fundamentales del pensamiento de Heidegger es el de Dasein. Un término cuya pretensión será distinguir el modo de ser del Hombre del de otros entes cuya esencia sería distinta a la humana. Pero, como se sabe, lejos de pretender constituirse en una antropología filosófica (cfr. Heidegger, 2001, $\S 10)$, esta aclaración del Hombre fungirá como vía para plantear la pregunta por el sentido del ser en general: la pregunta propia de una ontología fundamental (cfr. Heidegger, 2001, p. 13).

Así, la utilización del concepto "Dasein" parece inscribirse en una tarea muy diferente a la de meramente corregir una interpretación histórica insuficiente del ser humano, por muy importantes que puedan ser los aportes de esta última. En términos negativos, la formulación de lo humano como "Dasein" se presenta más bien como la oportunidad de superar una determinación del mismo en cuanto una "mera cosa" presente en un espacio. Las raíces históricas de tal concepción se encontrarían, a juicio de Heidegger (cfr. 2001, p. 48), en la determinación aristotélica del Hombre en cuanto que zôon lógon échon, ${ }^{1}$ y el modo como ésta fue heredada y reformulada en su comprensión moderna, cartesiana, en el sentido de animal rationale (cfr. Perrin, 2010). Teniendo tal definición como horizonte comprensivo de lo humano se le terminará por concebir al modo de un subjectum, esto es, como aquello que, hallándose permanentemente presente, subyace a diversas propiedades de carácter racional (cfr. Heidegger, 2001, p. 46).

Tal comprensión occidental del ser del Hombre terminaría por constituirse en una obviedad incuestionable que lo entenderá según el modo de ser de la mera presencia espacial (Vorhandenheit), lo cual albergaría, ante todo, el peligro de dejar su ser auténtico en una indiferenciación absoluta respecto de cualquier otro ente de la Naturaleza. Y es que si todo lo natural es al modo de un mero

1 A partir de la figura mítica de Jano, Figal (2007, p. 61) ilustra el doble significado que Aristóteles tendría para Heidegger. Éste no solo representaría el inicio de una metafísica occidental que erraría en los planteamientos de sus preguntas fundamentales, sino que, a la vez, sería aquel punto de inflexión que podría situar al pensar en la "verdad de la vida", esto es, en aquel suelo radical desde el cual acceder a los asuntos filosóficos. 
hallarse presente en un espacio, entonces bien, el Hombre, siendo él mismo un ente natural, deberá ser, en sus caracteres fundamentales, indistintamente, de este mismo modo: una mera cosa. Por tanto, el problema principal de la formulación tradicional de Hombre para Heidegger es que ésta, en última instancia, terminaría por ocultar un fenómeno fundamental, a saber, la íntima relación de lo humano con el ser. Así es como Heidegger, en los años 60, reconstruirá su propio pensamiento, diciendo: "Mi tesis es: que la esencia del hombre es comprensión de ser (Seinverständnis). Yo puedo hacer una experiencia de la esencia del hombre a partir de esta comprensión de ser" (1994b, p. 260). Por tanto, mientras que esta relación entre el hombre y el ser no haya sido explicitada, jamás se podrá llegar a plantear la pregunta por el sentido del ser mismo desde la radicalidad del existir humano.

Dicha necesidad de volver a lo humano para llevar a cabo una aclaración del ser es lo que Heidegger ya habría advertido en la propia filosofía griega. En efecto, siendo para los griegos tan fundamental el "hablar" (lógos), como posibilidad propia y exclusiva del Hombre (cfr. 2002, §13), y siendo mediante éste que el ente circundante saldría a la luz en lo que éste es, entonces, es el lógos, en cuanto que aletheúen, la posibilidad radical de "develamiento del ente" (1992, p. 133), esto es, su posibilidad primaria de manifestación. Por lo mismo, Heidegger debe insistir en el hecho que una comprensión de este modo de ser humano tan fundamental como es el hablar, tuvo que ser un requisito necesario para elucidar cómo es que el ente mismo pudo comparecer, es decir, llegar a ser. Es lo que se observa, por ejemplo, cuando Heidegger afirma: "Pero para ver, ante todo, la estructura antropológica en la cual se sostenía la investigación griega, se requiere el regreso al fenómeno del aletheúein, del abrir descubriente (aufdeckendes Erschliessen) del mundo" (1992, p. 370).

Lo anterior obliga a hacer una precisión importante. Comentando la traducción francesa de Sein und Zeit, Heidegger señala que el traslado de su término "Dasein" a la expresión francesa "êtrela" no aprehende su auténtico significado. Él mismo sugiere como traducción "être-le-la" (cfr. Heidegger, 1994b, p. 157; Beaufret, 1993, p. 24). En efecto, en la expresión "Dasein" en cuanto que "ser-ahí" resuena la idea de "heme aquí" (me voilà) (Heidegger, 1964, p. 130), en el sentido implícito, podríamos decir, de un mero hallarse 
presente o contenido en este lugar, mientras que lo decisivo sería expresar que se es humanamente, en cuanto que un Ahí. Esta es la razón por la cual en los planteamientos heideggerianos la expresión "Dasein" parece vincularse más bien al fenómeno griego de la alétheia como el referido de-velamiento (cfr. Courtine, 1998, p. 103) del ente, que a la tradicional problemática del Hombre como una esfera subjetiva particular. En efecto, el modo como a lo humano le es dado ser radicaría fundamentalmente en apartar al ente de su retraimiento para dejarlo comparecer ante sí mismo sin velo alguno que nos lo encubra. Entonces bien, "Dasein" es un concepto que indica, en cuanto que ámbito de-velador del ente, de su misma "realidad", el despliegue mismo del Ahí en el que, a su vez, habita. En otros términos, el "Dasein", lo propiamente humano para Heidegger, radica en lo que éste en Sein und Zeit denominará "aperturidad" (Erschlossenheit). ${ }^{2}$ Así, "el Dasein es su aperturidad" (2001, p. 133), es decir, el Dasein se ejecuta como la proyección misma del Ahí, siendo, necesariamente, ese Ahí que abre como su espacio vital. En este contexto se puede afirmar que "Dasein" es un término cuyo eje temático refiere, en última instancia, al problema del origen de lo que deberemos entender por nuestro Ahí o, dicho de otra manera: indagar en el problema del Dasein implica indagar, finalmente, en el problema de la constitución misma del mundo.

Ahora bien, esta tarea de indagar en aquella relación propia entre el existir humano y la constitución de su mundo, no podría pasar por alto otra dimensión fundamental, esto es, una consideración del ser mismo del Dasein. Y es que el modo como éste sea ha de considerarse determinante en la manera como a éste le estaría dado abrir su propio Ahí. Heidegger es enfático en determinarlo como el cuidado (Sorge) (cfr. 2001, §41), esto es, "El Dasein es un ente, al que en su ser le va este mismo" (2001, p. 191). Sin embargo, tal expresión pareciera apuntar

2 Volpi desarrolló en extenso la relación entre el pensamiento de Heidegger y el de los griegos, principalmente, Aristóteles. Destacando el enraizamiento de la verdad o falsedad de la predicación (lógos apophantikós) en lo que él denomina la "disposición descubriente" del Dasein, éste vinculará su "ser develante" (aletheúein) con el término heideggeriano "aperturidad" (Entschlossenheit) (cfr. Volpi, 2012, pp. 84 y ss.). De esta manera, Volpi subraya aquella rehabilitación de la praxis, en el sentido de la phrónesis aristotélica, como el ámbito de develación, entendiéndola como un comportamiento (hexis) en el que habitaría y se ejercería la verdad mediante el lógos (meta lógou) (cfr. Volpi, 2007, p. 230). 
a una reflexividad que poco pareciera aclarar sobre la articulación del ente con el cual éste se confronta cotidianamente: el ente del mundo circundante. ¿Cómo pensar, pues, la relación entre aquel movimiento autorreflexivo humano que Heidegger pareciera señalar en el cuidado y la apertura del Ahí en el cual éste mismo habita? En otros términos: ¿cómo es que el "cuidado", ahora entendido como el ser mismo del Dasein, pertenece al problema de la constitución del mundo? Si esa realidad, si lo que está siendo no es en su totalidad un fenómeno simple, sino tan complejo que se nos presenta como una vasta multiplicidad de entes, delimitados espacio-temporalmente, ¿qué es lo que indica el cuidado en el contexto de una relación con el espacio, con el tiempo, y con los entes espacio-temporales?

Como se advierte, tales preguntas se traducen, en última instancia, en la tarea de entender cómo es que, desde los planteamientos heideggerianos, es factible pensar la íntima relación que el existir humano guarda con el problema del "inicio" mismo de nuestra realidad, y cómo es que la consideración del fenómeno del cuidado sería decisiva para entender tal relación. Estos serán, pues, los problemas que quisiéramos abordar en las siguientes reflexiones, en un intento de pensar en concreto, desde la noción heideggeriana del Dasein, cómo es que se llega a comprender la existencia misma como "inicio" de la realidad en general con la cual nos confrontamos cotidianamente.

\section{El fenómeno de la diversidad de la realidad sensible}

En lo que sigue, pues, intentaremos comprender, desde los planteamientos heideggerianos, la manifestación de lo que nos comparece en su estrecha relación con lo humano. Mas, será importante hacer una precisión. Y es que el pensar de Heidegger parece ser uno tal que siempre se ha atenido a la concretud del existir humano. Su referencia a casos prácticos cotidianos en Sein und Zeit, como inicio de las reflexiones acerca de los existenciarios que componen al Dasein mismo, parece ser un modo ejemplar de llevar a cabo una consideración filosófica siempre atenta a una confrontación con los asuntos mismos. Téngase en cuenta, por ejemplo, el caso del martillo y del martillar, desde los cuales aparecen momentos como 
la circunspección articulada desde un para-algo (Wozu) en cuanto carácter del "mundo" que el propio Dasein es en cuanto ser-en-elmundo (cfr. Heidegger, 2001, §15) Y, sin embargo, en tales casos, son escasas las referencias a aquel nivel donde acaece el aparecimiento más concreto del mundo, esto es, su aparición sensible.

Las presentes reflexiones, no obstante, pretenden entender lo humano como instancia de-veladora del mundo, justamente, desde dicho nivel: la sensibilidad. Y es que el hecho de afirmar que la percepción sensible es, en efecto, el ámbito de presentación de lo que entendemos por nuestra realidad concreta e inmediata no parece sino justificar su inclusión en la problemática misma de su propia apertura. En efecto, en ella es que se manifiesta a la vida humana aquella realidad con la que ésta cotidianamente trata. A nuestro juicio, es a partir del aparecimiento más concreto del ente, su presentación sensible, que puede ser, en efecto, factible advertir en qué medida el existir abre mundo y cómo es que su manifestación, en última instancia, se fundaría en el modo de ser humano que Heidegger denominara "Dasein".

Ahora bien, como mencionábamos, no son muchas las oportunidades en las que la percepción sensible es referida por Heidegger como centro de las problemáticas que competen al existir. $^{3}$ Sin embargo, en aquellos momentos en los que éste lo hace, se aprecia el esfuerzo por realzar aquellos rasgos que pudieran ser considerados propiamente existenciales, dejando de lado una comprensión del fenómeno de la percepción como una actividad meramente pasiva, mecánica, a la manera de una recepción de meros "datos sensoriales". A propósito de Aristóteles, Heidegger señala: "Aisthesis no puede traducirse como 'sensación', aisthesis quiere decir simplemente 'aprehender' (Vernehmen) el mundo, la manera de tenerlo-a-él-ahî" (2002, p. 52). En el contexto de tal aclaración es que Heidegger pone en seguida el fenómeno de la sensibilidad en dependencia con la aperturidad (Erschlossenheit). Por otra parte, en

3 Kontos (1996) es quien ha logrado sistematizar una fenomenología de la percepción desde los planteamientos de Heidegger explicitando en detalle la pertenencia de la percepción a la mirada circunspectiva (Umsicht) vinculándola, justamente, con la temporalidad propia del existir. Por su parte, Ramón Rodríguez (2014) indaga en el fenómeno de la percepción en Heidegger para develar su horizonte comprensivo. 
Sein und Zeit, Heidegger menciona brevemente el problema de los sentidos al margen de la noción de "afección", como un modo en el que el Dasein es concernido por el ente. En este caso se menciona un "estar referido al mundo, que abre (erschliessend), desde el cual puede comparecer lo que nos incumbe" (2001, p. 137). Ahora bien, siendo explícita la relación entre percepción y aperturidad, las aclaraciones no van más allá de simples referencias, lo que hace imposible comprender en detalle la dependencia aludida. Sin embargo, en el contexto de la filosofía kantiana, particularmente en la lección Phänomenologische Interpretation von Kants Kritik der reinen Vernunft (1927/1928) hay mayores indicios de esta problemática, y son los que, a nuestro parecer, pueden ser de gran utilidad para seguir en concreto la manifestación del mundo desde el ámbito de aquella aperturidad que, como decíamos, es el Dasein mismo. Dicho texto, por tanto, servirá de fuente para las siguientes aclaraciones, mas no se pretenderá realizar una exposición de la lectura heideggeriana de Kant. ${ }^{4}$ Nuestro interés, más bien, es atender a los casos perceptivos precisos allí expuestos con el fin de entresacar aquellos momentos existenciales de la sensibilidad que aportan aquella base necesaria para pensar la tesis heideggeriana del Dasein como apertura. Esta vía es la que, a nuestro modo de ver, puede aportar a una comprensión efectiva de la relación entre el existir humano y la manifestación de su realidad.

Ahora bien, cabe, por último, advertir que estas reflexiones tomarán como punto de partida la percepción inscrita al ámbito de lo que Heidegger denomina "mundo circundante" (Umwelt) (2001, p. 66), por lo cual deberán dejar de lado el aparecimiento del otro, es decir, la presencia "intramundana" del Dasein. Dicho fenómeno, en efecto, no se agota en la sensibilidad. La "visión" de otros existentes, en el caso de Heidegger, requiere un análisis del "ser-con" (Mit-sein) como momento constitutivo del existir, lo cual

4 Cabe destacar que la interpretación heideggeriana de Kant es un problema en sí mismo y gira en torno a la disputa que Heidegger habría mantenido con la escuela neokantiana. Conocido es el reproche que hace Heidegger a ésta por el hecho de haber reducido la obra de Kant a una teoría del conocimiento, cuando su interés, a su juicio, habría sido llevar a cabo una ontología propiamente tal del Hombre (cfr. Cassirer, 1931). Para una profundización en las lecturas de Heidegger sobre Kant, cfr. Sherover (1971), y las obras compilatorias editadas por Rockmore (2000) y Strube (2009). 
implica la explicitación de la constitución de una "comunidad del futuro", lo cual es de suyo un tema que requiere un estudio propio (cfr. Heidegger, 2001, §26; Johnson, 2010).

Así, pues, para comenzar, cabe preguntarse: ¿qué es lo que se manifiesta mediante nuestra sensibilidad? Los sentidos nos proporcionan un sinnúmero de entes particulares, tales como casas, sillas, paisajes, etcétera. Nos ofrecen, a la vez, matices diversos en esas mismas cosas, como colores, claroscuros, suavidades, asperezas, que conforman su aspecto. Todos y cada uno de estos incontables entes, exhibiéndose diversamente ellos mismos, nos ofrecen determinadas posibilidades de trato. La percepción sensible es un ámbito de la vida humana en la cual acaece el cambio, la particularidad, la diversidad. En una palabra, inmersos entre las cosas, viviendo con ellas, lo que se percibe es fundamentalmente multiplicidad (cfr. Heidegger, 1995, p. 343). Pero ¿esta "percepción de la multiplicidad" puede ser explicable desde el sinnúmero de "sensaciones" que parecieran provenir del ente percibido? ¿Es lo percibido responsable de su propia diversidad? Como señala Heidegger, siguiendo a Kant: "el hecho que algo así como un múltiple (ein Mannigfaltiges) se nos ofrezca, no es del todo ni en absoluto obvio" (Heidegger, 1995, p. 344).

Entonces bien, ¿qué es aquello que pertenece a la percepción sensible y que le otorga dicho carácter múltiple? Tomemos como caso la percepción visual. Prestando atención, por ejemplo, a un árbol, es posible apreciar en su aspecto general diversos matices sensibles. El verde de su follaje, de hecho, no es homogéneo, sino que allá y acá se percibirán tonalidades verdosas más claras o más oscuras. "Ahî", podemos decir, hay más sombra que "allá", mientras que "aquî" el verde es más claro que "acá". La visión se traslada desde un punto a otro, y en cada estación, en cada fase perceptiva, la propiedad luminosa y cromática del árbol ha variado. Mas, para que este traslado de la atención en determinadas estaciones se efectúe, ha sido necesario recorrer una extensión. En un punto específico donde la mirada se haya detenido se advertirá una sola configuración luminosa y cromática, mientras que "al lado" o "en la cercanía" o "lejanía", se presentará otra diferente. Como vemos, los adverbios "acá" o "allá", con los cuales describimos el recorrido de la atención por los distintos datos sensibles del árbol aluden a una determinada 
espacialidad. Dicha espacialidad sería la que nos permite advertir que lo que se observa en un punto difiere de lo percibido en otro. En efecto, el "más verde" o "el menos oscuro" se determinan según una comparación entre determinados sectores percibidos. De esta manera, la particularidad sensible de cada punto del árbol requiere de la co-percepción de un "acá", un "allá", etcétera, que permita la distinción y, por lo mismo, la percepción de la diversidad. Así, en palabras de Heidegger: "la diferencia mutua es justamente una tal que es propia, determinada cada vez por el lugar y la posición” (1995, p. 127). La percepción sensible, en consecuencia, requiere relaciones espaciales para ejercerse como presentación de la diversidad. Y así como en el caso de la "multiplicidad", el fenómeno espacial que expresamos como "acá" o "allá" tampoco parece ser un "asunto" de la cosa, sino más bien "nuestro", pues, para "nosotros" es que las percepciones se hallan "cercanas" o "lejanas" espacialmente. El espacio, en fin, sería un constitutivo de nuestra percepción y es el que, por lo pronto, permitiría la diversidad de lo "percibido" (cfr. Heidegger, 1995, p. 128).

Ciertamente, tal diversidad de la percepción sensible ha de poseer un momento necesario como es el espacio. Pero, el hecho de que se pueda decir que "acá" el verde es más oscuro que "allá" no es reductible solo a relaciones espaciales. Y es que cuando se advertía que el "verde" de "allá" es más claro que el de "acá", "comprendemos" tácitamente que "este verde" que "ahora" vemos es diferente al de "antes". El recorrido y detención de la atención en algunos de los puntos espaciales requiere, a su vez, la comprensión de lo percibido como una sucesión en cuanto que "anterior" o "posterior". Sin la noción de un "antes", un "ahora" y un "después", la percepción de las configuraciones sensibles como "sucesivamente otras" no podría acaecer. En términos kantianos, Heidegger señala: "Observando, debe el ánimo (Gemüt), ya sea explícitamente o no, decir siempre ahora - ahora - ahora" (1995, p. 344). Así, en cada uno de los instantes perceptivos, el contenido de lo percibido se debe dar necesariamente de manera distinta. El "antes", el "ahora” y el "después", entendidos, por tanto, como una sucesión de ahoras, son modos como el contenido múltiple puede otorgarse, en cuanto un "antes, acá" o un "ahora, allá”. Según tales relaciones de ahoras, en los cuales lo observado 
se particulariza, se hace, entonces, posible la distinción y, por ende, la mostración de una diversidad de sensaciones. Así, la diversidad sensible requiere también el tiempo: "Pues -acota Heidegger- cada ahora es también un ahora-no-más, un recién (Soeben), y fue antes justamente un en este momento (sogleich), i. e., ahora la impresión en sí es ya recién de aquella y era próximamente anterior de esta" (1995, p. 345).

Como se advierte, espacio y tiempo constituyen la "multiplicidad" propia de la percepción sensible. Dicha multiplicidad, según lo anterior, se constituye a partir de la co-percepción al modo de un "acá", "allá", etcétera, que siempre ha de mostrarse en cuanto que un "antes", "ahora" o "después". Cabe destacar esta íntima relación entre el espacio y el tiempo en la constitución de la multiplicidad sensible que presenta lo percibido. Todo "acá", "allá", etcétera, co-percibido en la donación de las diversas configuraciones sensibles, se nos ofrece al modo de un "antes, acá", un "ahora, allá" y un "después, ahî". Podemos decir, entonces, que dicha relación entre espacio y tiempo es la condición de posibilidad de la donación del ente sensible. Ahora, ¿cuál es su propio fundamento, es decir, hay un origen desde el cual dicha relación entre las relaciones espaciales y temporales emerja?

Otro caso tomado de la percepción sensible puede ayudar a encontrar una vía de acceso a dicho fundamento. Recorriendo la diversidad luminosa y cromática que nos ofrecía el árbol de nuestro ejemplo, podemos distraernos y observar a un ave que vuela sorpresivamente desde su ramaje. La atención ahora se dirige a un nuevo ente, aunque podemos ciertamente regresar al árbol. Este volver a mirar nuevamente el árbol es un fenómeno que debe ser aclarado. Y es que en este caso la percepción sensible ha seguido cumpliendo su función de ofrecer multiplicidad. Atendiendo al ave, escuchamos el ruido del aleteo, el cual, por cierto, no es homogéneo; nos detenemos un momento en su aspecto en movimiento para ver de qué animal se trataba. Distraídos con el ave, la diversidad sensible del árbol ya no se presenta, pues ahora se trata de aquella que pertenece al animal. En el regreso al árbol, en cambio, la percepción vuelve a mostrarnos claroscuros o matices cromáticos variados.

La pregunta es si el modo de ser de la precepción sensible explica el hecho de que, al regresar al árbol, los diversos datos sean 
percibidos como los que observábamos "antes" en ese árbol. Por lo pronto, la multiplicidad propia de la percepción sensible solo parece proporcionar datos actuales, esto es, ahoras perceptivos sin una conexión necesaria entre ellos. A propósito de lo anterior, y en el contexto kantiano, Heidegger señalará que, en tal caso, "el ánimo caería, luego, constantemente de una fase del ahora a una otra totalmente desconectada, de manera que lo anterior simplemente se perdería" (1995, p. 351). Así, según nuestro ejemplo, si el "árbol" observado se eliminase totalmente en la observación actual del ave, y se convirtiese en una nada absoluta, un regreso a éste sería imposible. Dicho de otra manera, en la nueva percepción, lo "percibido anteriormente" deberá conservarse de algún modo, de lo contrario, perdidos en cada fase perceptiva erraríamos de un "ahora" a otro, sin que lo "anterior" pudiese ser retomado como objeto de nuestra atención: desde el presente, ya no regresaríamos al ente, sino que lo veríamos "por primera vez", pues, no entenderíamos que se trataba de aquello "antes visto" (cfr. Heidegger, 1995, p. 351).

Entonces bien, se hace necesario pensar que, durante la observación de un nuevo objeto, aquel que antes observábamos debe ser "retenido", es decir, hallándose ausente sensiblemente, ha de conservarse como un ámbito de lo "antes visto", pues, de lo contrario, no sería posible regresar a él en cuanto "el mismo objeto de antes". Empero, esta posibilidad ya no pertenece a la percepción sensible, y justamente esto es lo decisivo para nuestra discusión. Podemos advertir que la donación de la realidad inmediata no se agota en la multiplicidad de la sensibilidad. En ella se juega también una posibilidad de retención (Behalten) (Heidegger, 1995, p. 352) de lo que percibíamos. En palabras de Heidegger, debe haber una "posibilidad de libre conexión de lo que se ofrece más allá de la fase de lo percibido actualmente" (1995, p. 351). Esta retención, por tanto, es la que nos permitiría "regresar" a lo que percibíamos, también es la que posibilitaría traer lo observado al presente (Vergegenwärtigung)

5 A pesar de que las presentes explicaciones heideggerianas se abocan al fenómeno kantiano de la "Reproduktion" (cfr. Heidegger, 1995, \$24 c), remitimos al concepto husserliano de "Retention", dando énfasis al carácter intencional y eminentemente temporal que caracteriza a esta conciencia originaria cuya función es contener lo "pasado" en la aprehensión actual (cfr. Husserl, 1928, §12). 
sin necesidad de su presencia actual y, a su vez, es la que permitiría complementar con nuevos datos lo ya visto. ${ }^{6}$

No obstante, la aludida multiplicidad de la percepción sensible y la posibilidad de retención no acaban por agotar la manifestación del ente que nos comparece en la realidad que nos rodea. Hasta ahora se ha discutido que las fases perceptivas arrojan una diversidad sensible que, a la vez, se "retiene", de modo que la atención pueda regresar a lo "ya visto", reproducirla, o "complementar" lo "antes visto" con nuevos datos sensibles. Sin embargo, la relación que se produce entre la percepción sensible y la retención exige haber entendido que lo "antes" y lo "actualmente" percibido sean lo "mismo". Sin la comprensión de la "mismidad" del ente, la retención de sus cualidades o la comparación entre ellas perderían su suelo. La posibilidad de la retención implica, así, una identidad de lo retenido. Asimismo, la percepción de una multiplicidad sensible igualmente requiere que toda la variedad presentada sea de lo "mismo". El fenómeno de la percepción parece fundarse, entonces, en un acto más radical aún que las relaciones de espacio y tiempo comentadas, a saber, una identificación (Identifizierung) (cfr. Heidegger, 1995, p. 361). Dicha identificación, por ende, no puede ser el resultado de la retención y de la percepción sensible, pues, sin comprender que lo antes y ahora percibido son lo mismo, ambas se anularían. Antes de percibir lo que nos rodea, se requiere una comprensión de la identidad. La "mismidad" no es, por tanto, sino una instancia previa a la manifestación sensible de la realidad?

6 Las consideraciones sobre la percepción que se exponen desde la lectura de Heidegger sobre Kant parecen estar profundamente emparentadas con los análisis de la percepción propios de Husserl, sin que pareciera integrarse nada nuevo a los mismos. No obstante, en lo que sigue veremos que la gran inflexión heideggeriana a dichos análisis corresponde a la incorporación de la posibilidad del existir, es decir, al futuro, como horizonte de la percepción. Por su parte, Kontos (cfr. 2006, cap. I) lleva a cabo una delimitación de los puntos comunes y de las divergencias que existen entre las descripciones de la percepción tanto de Heidegger como de Husserl.

7 El carácter previo que destacamos de la identificación atiende a la inflexión que Heidegger realiza en la filosofía kantiana. Luego de explicar las síntesis de la Apprehension y la Reproduktion, y de vincularlas con el presente y el pasado, respectivamente, éste abordará la por Kant denominada Recognition, esto es, la posibilidad de percibir al ente presente como el mismo del pasado. No obstante, Heidegger advierte que el término es "equívoco" (cfr. Heidegger, 1995, p. 361), ciertamente, porque con él se sugiere un "volver" a conocer, que debería ser entendido como posterior, mientras que ambas síntesis requieren tal 
Pues bien, en dicha mismidad ha de fundarse la aparición de cada "cosa sensible" que nos comparece. Ella parece posibilitar la diversificación que caracteriza el acto de la percepción. En virtud de lo "mismo" es que puede haber distinción y diversidad. Esta identificación previa ha de ser entendida, entonces, como la unidad última que permite la multiplicidad perceptiva. Así es como nos hallamos en aspectos primarios de la presentación de la realidad y la característica multiplicidad que servía de inicio para estas discusiones. Y, como se destacaba, estos no son asunto de lo que se muestra, sino que, ante nada, son un "asunto nuestro".

Entonces bien, ¿qué significa que las relaciones espaciales, temporales y de identidad, entendidas como fundamentos del carácter diverso de la sensibilidad, sean "asunto nuestro"? Hasta acá, el planteamiento del problema de la realidad en sentido general, es decir, de lo que "siendo" nos comparece, ha sido el de reconducir la diversidad de la misma a la percepción sensible. Esto nos ha mostrado que la infinita multiplicidad de datos es un fenómeno fundado en instancias propias de la sensibilidad. Estas relaciones nos muestran, así, lo decisivo, a saber, que esa realidad con la cual la vida se confronta es tal únicamente según dichas relaciones. En otras palabras, el caso de la percepción sensible nos ha mostrado que el sentido de aparición de la realidad es "nuestro sentido" y, por lo mismo, podemos concluir que el modo como el mundo -nuestro mundo- se abre, es según como el Hombre, de acuerdo con su propia constitución, "lo abre". La realidad, podemos afirmar con lo anterior, es realidad humana, pues lo "mundano" de dicha realidad conforma el modo de ser del Hombre. Por esto es que las relaciones espaciotemporales y de identidad son "asunto nuestro", a saber, porque, en última instancia, nos pertenecen y conforman en lo que somos.

En fin, estas discusiones nos muestran en mayor detalle que el problema de lo humano implica el de la constitución de la realidad. En el marco de estas advertencias es que la determinación heideggeriana de Hombre como "ser-el-ahî" comienza a mostrar su

identificación. Así, la posibilidad de re-conocer al ente como "lo mismo" correspondería, más bien, a un "pre-tener" (Vorweghaben): al futuro. Por ello, Heidegger subraya que sería más adecuado "denominar a esta síntesis una tal de la pre-cognición (Prae-cognition)" (Heidegger, 1995, p. 364), es decir, un pre-conocimiento desde el poder-ser. 
respectivo derecho. Con esto, ya podemos entender que lo humano sea, como lo veíamos en Heidegger, el ámbito de apertura de su mundo. A continuación deberemos comprender, sin embargo, cómo se ejerce este movimiento de apertura. Los análisis conducen al ser del Dasein mismo, a aquel que desde Heidegger referíamos como cuidado. Nuestra pregunta es, por tanto: ¿cómo es que el cuidado es, entonces, constitutivo del mundo, de la realidad en la cual nos encontramos diariamente?

\section{El futuro como articulador de mundo}

El Dasein, siguiendo a Heidegger, es su "aperturidad". Dicha aperturidad ha de ser el ámbito donde se posibilita nuestra realidad. La tarea será entender, por ende, cómo es que este acto de apertura acontece.

Resulta una obviedad afirmar que la observación de las diversas cualidades presentadas por un objeto percibido muestra un trascurso cronológico. El "antes" de la percepción se refiere a la observación en el pasado. Las observaciones actuales corresponden al presente. Y, las que luego se realizarán, pertenecen al futuro. La secuencia pasado, presente y futuro permite darle un orden a los actos atencionales. No obstante, ¿se corresponde este orden cronológico con la temporalidad en la que se despliega la percepción? ¿Efectivamente, ésta se realiza desde el pasado, pasando por el presente, hacia un futuro? Esto es: ¿acaece primero el "antes", en segundo lugar el "ahora” y, en tercer lugar, el "después" en la percepción de un objeto?

Si esta secuencia correspondiese al auténtico sentido temporal de la percepción, la determinación de un "antes" no sería tal, pues, ¿"antes de qué" sería este momento caracterizado como "anterior"? Asimismo, respecto al "después" cabría plantearse la misma pregunta. "Antes" y "después" son más bien términos relativos comparativos (cfr. Brentano, 1976, p. 128), es decir, suponen un punto de referencia desde el cual puedan determinarse en cuanto que "anteriores" y "posteriores", y éste no puede ser sino aquel "ahora”, cuando observo tales propiedades. En vista a la actualidad de un ahora se determina lo pasado y lo venidero. En el fenómeno de la percepción sensible se anuncia, entonces, cierto "ahora" que parece delimitar una secuencia temporal entre lo "anterior", "actual” y "posterior". 
Planteado así el problema, llama la atención que dicho "ahora" no pueda identificarse sin más con el ahora puntual de la fase perceptiva en la que se reciben directamente datos sensibles. En efecto, este nuevo "ahora" parece exceder los límites de la actualidad perceptiva para abarcar un pasado y un futuro, mientras que el "ahora" de la fase perceptiva se limitaba a la actualidad de la observación. Por lo pronto, podríamos decir que se trata, más bien, de un "presente" que encierra en sí mismo un antes, un ahora y un después. De hecho, todo el acto de observación de lo percibido, él mismo, radica en constituirse en un "presentarse", o lo que el mismo Heidegger denomina "Gegenwärtigen von etwas" (1997, p. 380). Podemos formularlo así: ahora, que observo el árbol, he visto claroscuros, veo un verde más intenso y veré otra variedad de aspectos. Este "presente", por tanto, no puede identificarse con un segmento de una secuencia cronológica, sino que es el "momento" de la observación misma. Dicho "momento", no obstante, ha de ser entendido propiamente como aquel constituyente de la articulación temporal de la percepción, vinculando los "antes", "ahoras" y "después" como una unidad total que entendemos como la "experiencia de observar". Dicho "presente", según se advierte, sería más bien caracterizable como una "situación", donde se exhibiría una determinada linealidad secuencial. La diversidad cronológica al modo del "antes", "ahora" y "después" parece fundarse, por tanto, en una unidad situacional: en un cuándo determinado.

Mas, dicho "cuándo" es el fenómeno que lleva a una consideración del tiempo más allá de su sentido fáctico, y lo deja entender en su carácter eminentemente trascendental. Heidegger señala: "La temporalidad (Zeitlichkeit) se temporiza en la respectiva unidad de futuro, pasado y presente" (1997, p. 376). En otras palabras, si el tiempo que ahora aparece en las discusiones es configurador de la consecución "pasado", "presente" y "futuro", no puede, él mismo, ser lo constituido. Éste ha de ser entendido, entonces, como un acto de apertura. En efecto, él es, pues, mi "instante", el mismo que en Die Grundprobleme der Phänomenologie (1927) aparece en directa relación con el kairós aristotélico (cfr. Heidegger, 1997, p. 409), el cual Heidegger caracterizará como "la totalidad de las circunstancias, el cómo, cuándo, para qué y sobre qué” (2002, p. 171). Se advierte, por lo mismo, un tipo de temporalidad que despliega, que 
configura la donación, y que, como tal, tiene un carácter activo. Es un tipo de temporalidad que siempre está "fuera de sî", articulando "exterioridad", aquella en la que vivimos. Es en este punto donde es posible detectar una bifurcación que parece caracterizar el acto de la percepción de un objeto.

En efecto, hasta el momento se trataba de aclarar la relación directa con el ente percibido, sin embargo, en estos momentos aparece la instancia en la cual tal relación perceptual parece acaecer en propiedad: el tiempo, aquel que se temporiza abriendo al Ahí. En palabras de Heidegger, se trata del tiempo ek-stático (2001, p. 329). En él se fundaría la diversidad de lo aperiente, aquella con la que se confronta la vida: la realidad. Así, los análisis se ven conducidos a un modo de tiempo que solo puede pertenecerle a un ente que él mismo sea aperturidad, es decir, "acto" de constituir su "mundo": el Dasein mismo. Dicha temporalidad será, entonces, la que ha de constituirnos en cuanto que humanos.

A partir de lo anterior, la tesis heideggeriana que afirma que lo propiamente humano es el Dasein y su aperturidad comienza a mostrar su sentido propio, a saber, su íntimo carácter temporal. Dicha aperturidad es, en efecto, el todo del aparecimiento, el sentido completo de la aparición concreta del ente con el cual el existir se confronta. Dicha aperturidad sería, por tanto, el horizonte en el cual acaece el propio presente del existir, en el cual el Dasein es, descubriendo al ente mismo y, por lo mismo, percibiéndolo. Dicho presente abierto y posibilitado por el tiempo originario es el que Heidegger llamará "instante": "El presente que es contenido y emerge desde la aperturidad es el que llamamos instante (Augenblick)" (1997, p. 407). En dicho horizonte temporal se abre, en consecuencia, aquel "ahî" en el cual la vida se despliega. En el tiempo se desplegaría el mundo del existir, es decir, el modo en que la diversidad material propia de la realidad se nos presenta intra-mundanamente, esto es, al interior de nuestro mundo. Debemos preguntar, en consecuencia, ¿qué sentido tiene este tiempo configurador de realidad? ¿Se trata de un mero contexto estático o él mismo se exhibe como un movimiento? Y si lo último fuese el caso, ¿qué clase de movimiento es el que está en juego en estas consideraciones acerca de la constitución de la realidad? 
Será decisivo detenernos en la caracterización heideggeriana de la aperturidad misma como aquella que "contiene" al presente (Gegenwart) (cfr. Heidegger, 1997, p. 407). Se decía, pues, que el instante parece contener las diferentes fases temporales que en última instancia permitían la multiplicidad del ente percibido. Mas, dicha contención no es una conglomeración, es decir, no reúne a la diversidad sin que en ella haya vinculación interna alguna. La contención del instante es, más bien, el sentido de su íntima unidad. Dicho de otra manera, el instante se despliega como un modo de contención; aquel que otorga la posibilidad de volver a un "antes", posicionarnos en un "presente" y prever un "después", inmersos en una misma situación. Empero, se afirmaba más arriba también que la posibilidad última del "antes", "ahora" y "después" venía dada mediante un acto de identificación. La "mismidad" de lo dado era aquella instancia de la aparición de la realidad que debía acontecer previamente a su percepción. Así es como resulta factible afirmar que la identificación y la contención parecen, entonces, estar en una estrecha relación como instancias fundantes de la aparición de la realidad. Es más, se puede advertir que en la medida en que se trata de lo "mismo" es que la contención parece tener lugar. En definitiva, el instante, en el cual acaece la realidad y su multiplicidad sensible, se presenta, ante todo, como una identificación de lo mismo que contiene y reúne lo dado en él.

Ahora bien, ¿cómo es que este movimiento de unificación y contención de lo mismo acaece?

La problemática apunta precisamente a la extensión (Erstrecktheit) que, en los planteamientos heideggerianos, exhibe el tiempo vivido. A propósito del ahora, Heidegger dirá que éste "siempre tiene una cierta amplitud temporal (zeitliche Weite), se relaciona con un ahora, por ejemplo, hoy en la tarde, cuando conversamos entre nosotros. Incluso podemos decir: en este invierno pasa esto o aquello" (1994b, p. 60).

Si bien es cierto que en los planteamientos heideggerianos se destacan otros tres caracteres del tiempo vivido, a saber, la significatividad (Bedeutsamkeit), la databilidad (Datierbarkeit) y un carácter público (Öffentlichkeit) (cfr. Heidegger, 1997, §19 ß; 2001, 
§79), quisiéramos prestar atención a la referida amplitud temporal o extensión. Dicho carácter es, pues, aquel que puede conducir estas discusiones al horizonte temporal propio del Dasein (cfr. Fleischer, 1991). Cuando se dice, siguiendo a Heidegger, "este invierno pasa esto o aquello", es claro que la unidad temporal "invierno", más allá de ser una determinación cuantitativa de meses, adquiere su carácter unitario en cuanto que una situación vital específica. Ciertamente, en dicho invierno ocurre esto o aquello, también se realiza tal o cual actividad, no obstante, la unidad recíproca entre las actividades y sucesos de ese "invierno" no vienen dadas desde ellas mismas. Heidegger piensa, en efecto, en la unidad temporal como un télos, es decir, un fin que unifica cada evento particular. Ejemplos cotidianos en las explicaciones de Heidegger son numerosos: "Quiero darle a mi amigo un regalo, quiero darle una alegría, este es el télos" (2002, pp. 59 y ss.), dirá éste en sus lecciones sobre Aristóteles. Con tal expresión se destaca que es en el horizonte de un fin que, según su ejemplo, algo así como "librería" puede comparecer como el lugar donde se adquirirá el regalo requerido. Así, la expresión "invierno" o "darle la alegría a un amigo" aluden a la extensión de instantes específicos, situaciones vitales fácticas en las que el existir humano ha de encontrarse, y cuya constitución en cuanto que unidades temporales debe ser entendida, ante todo, al modo de la consecución de una posibilidad propia. En efecto, tal consecución de lo que se pretende que finalmente ocurra es la instancia que reuniría los "antes", "ahora" y "después" particulares, en la medida en que se abren en un horizonte de identificación de la realidad cuyo sentido último es un determinado fin.

Los casos aludidos, en definitiva, muestran el sentido temporal de la caracterización de lo humano en cuanto "Dasein". Se trata de aquella apertura del ente delimitado según un horizonte que radica en una resolución a concretarse en cuanto que un fin o posibilidad específica. Dicho de otro modo, "Dasein" es una expresión que contiene ella misma el carácter temporal último del existir humano en cuanto que "ser-el-ahí", es decir, como acto de aperturidad. Heidegger mismo advierte que la expresión "Dasein" no es sino una abreviación de una caracterización más amplia: "Hablamos abreviadamente de la aprehensión (Verfassung) del Dasein y siempre mentamos junto a 
ella: en su manera de ser (in seiner Weise zu Sein)" (1994a, p. 209). Así, "Dasein in seiner Weise zu sein" correspondería a la caracterización heideggeriana total de lo humano.

En efecto, si al existir le es dado "ser su Ahî" como acto de donar, de elaborar su mundo propio, la expresión "en su manera de ser" o, "en la manera como ha de ser" parece señalar hacia aquel arrojo a la posibilidad propia o fin que entendíamos como el sentido unificador de la realidad que descubrimos fácticamente. Mas, no podemos entender el concepto de "posibilidad" como un abanico de expectativas que podrían presentarse a un individuo, y que este, por su parte, elegiría "indiferentemente", de acuerdo con la "arbitrariedad" de su voluntad (cfr. Heidegger, 2001, p. 144). La posibilidad (Möglichkeit) es ella misma constitutiva de la apertura que el Dasein actual es, en cuanto que dona sentido a su modo fáctico de concreción. Por ello, el Dasein no está abierto a todos los modos de ser posibles, más bien se trata de que un poder-ser concreto se ejecuta en cuanto que una apertura realizada, fundante de la realidad que el Dasein mismo es (cfr. Heidegger, 1994b, pp. 209 y ss.).

Más tarde, en Carta sobre el Humanismo, Heidegger insiste en que la posibilidad no es aquello que estaría en potencia de ser realizada, como "algo" presente, latente, en un determinado sujeto. Al margen de las categorías modales de la metafísica, que lo opondrían a lo "necesario" y a lo "real", el concepto "Mög-lichkeit" aludiría, más bien, a un sentido activo de poder, como movimiento de "lograr-se" en cuanto lo que "se es capaz de ser" (Ver-mögen). Así, Mögen será definido como "otorgar la esencia" (das Wesen schenken), ya que este "ser capaz" radica en un permitir-se, conseguir-se ser. La "posibilidad" en sentido heideggeriano, por tanto, debe entenderse activamente como "posibilitación" (cfr. Heidegger, 1976, pp. 316 y ss.). ${ }^{8}$

Volviendo, pues, a nuestra discusión, se puede afirmar, por tanto, que el Dasein es, en cuanto elaborador de su Ahí, según un modo concreto como ha de ser. Dicho "ha de ser" (Zu-sein) se presenta como el horizonte particular y propio de su despliegue: se trata de su esencia (cfr. Heidegger, 2001, p. 42). En este sentido, mientras

8 Ahora bien, propio de este texto, donde se anuncia el giro del pensar heideggeriano, es que se traspasará esta condición de posibilitación desde el Dasein, como aparece en Sein und Zeit, al Ser mismo. 
la expresión "ser-el-ahî" indicaría un estar en trabajo, en el acto de abrir el espacio vital -es decir, el mundo-, la segunda expresión, "en la manera como ha de ser", enfatiza el horizonte de aquel acto específico de aperturidad. Así, este "ha de ser", aquel Zu-sein, perteneciente a la formulación completa del Dasein, apunta directamente al tiempo. En concreto, aquel instante que es nuestro se ejerce en el sentido de lo que "aún no somos", pero que estamos en acto de resolvernos ser: lo humano muestra, en consecuencia, su carácter eminentemente futuro.

Desde el futuro, esto es, desde una resolución hacia una posibilidad, deberemos entender el acto de identificación del ente descubierto en su diversidad, en cuanto que una posibilidad prescribe y contiene en su identidad la diversa realidad que comparece a la vida concreta. En este "arrojo" a la posibilidad acaece la apertura del mundo, y desde él, del ente diverso con el cual la vida trata, gana la identificación el carácter previo que destacábamos. La comprensión previa del modo como el ente ha de mostrarse en su diversidad no puede sino ejecutarse como un aferrarse a la posibilidad que "aún no se es". Mientras el existir está resuelto a una posibilidad, el ente es descubierto como lo que contribuye o no a dicho poder-ser, y lo contiene en su identidad en el horizonte de tal posibilidad. Y mientras el existir se retenga a sí mismo en este poder-ser, se prescribirán determinados tratos con los entes que desde él se descubran.

En definitiva, el acto de identificación es previo, pues aquel poder ser que funge como horizonte del descubrimiento de los diversos entes es tenido de antemano por el existir al modo de resolverse hacia él. Aquel instante que somos, en definitiva, es aquel que se constituye desde un movimiento de consecución de una posibilidad, desde el cual se articula la mismidad, es decir, el modo como los entes serán descubiertos. Con esto entendemos, entonces, que el instante, como dice Heidegger, sea cada vez nuestro (2001, p. 42), pues, desde el arrojo a una posibilidad propia se descubre al ente intramundano en una identidad determinada, instalando a la vida en un modo de trato particular con aquello que en dicha identidad se despliega. En esto consiste su vitalidad, esto es, el carácter ekstático destacado anteriormente. Desde este movimiento es que el Dasein se posicionaría en su "ahí y ahora", y constituye un "antes" y un "después", es decir, un pasado, un presente y un futuro de carácter 
fáctico (cfr. Heidegger, 2001, pp. 408 y ss.) y, por ende, "derivativo" (cfr. Vigo, 1997, p. 150).

Estas consideraciones nos muestran el movimiento fundamental que resulta ser el Dasein como aperturidad: un aferrarse a un poder ser que despliega un horizonte de presentación, mi mundo, desde el cual la diversidad de entes comparece a la vida para tratar con ellos. En esto radica precisamente su modo de despliegue, su propio ser: aquel que Heidegger denominará "cuidado" (Sorge): "Anticiparse a sí mismo, estando ya en (el mundo), en cuanto que hallándose entre entes que le comparecen intramundanamente" (2001, p. 192). Justamente, la estructura tripartita que se devela en esta definición del cuidado es la que en estas discusiones ha estado constantemente en juego. En primera instancia, se advierte una dimensión futura, es decir, un "estar anticipado" (Vorweg-sein); luego, un "ser-en..." un mundo (Insein), en cuanto posicionarse como un modo de "apertura del ente"; y, por último, un "hallarse entre" (Sein-bei) los entes intramundanos, el cual, por cierto, ha sido el punto de partida de todas estas discusiones y que llamábamos, en sentido lato, la realidad percibida de carácter múltiple. Ahora bien, en términos heideggerianos, estas tres dimensiones del cuidado, entendido como el sentido de la aperturidad misma, se expresarán como "Existencialidad" (Existenzialität), es decir, el "estar anticipado"; "Facticidad" (Faktizität), señalando aquel "ser-en", al modo de posicionar un mundo y, por último, "Caída" (Verfallen), esto es, la dimensión en la cual el Dasein ya se encuentra "entre" los entes que él descubre en un modo específico de aperturidad (cfr. Heidegger, 2001, p. 193).

De estas tres dimensiones, decisiva resulta ser la Existencialidad, pues ella, como se ve, se presenta como el horizonte total del movimiento del cuidado. En ella se devela el sentido futuro del existir, por lo que ella sería la dimensión originaria de la constitución de la realidad al modo como ésta se nos presenta. Dicha Existencialidad realza, así, el sentido temporal de lo humano, según el cual se puede entender la constitución "temporal" de nuestra realidad. Así, atendiendo a las consideraciones anteriores, resta, entonces, preguntar: ¿en qué sentido esta temporalidad futura del existir termina por desplegar su realidad? 


\section{El cuidado: auto-apropiación y realidad}

Pues bien, un movimiento de consecución de una posibilidad aparece como posibilitador de aquella realidad diversa con la que la vida trata. Este es el sentido propio según el cual se despliega esta "aperturidad" que es el Dasein. Por tanto, dicho movimiento posee un carácter eminentemente futuro, como un tiempo ekstático, "ofrecedor" de mundo. Así, el horizonte en el cual nuestra realidad se despliega es el cuidado. Éste es, pues, el ser de la "aperturidad". El cuidado, como consecución del propio poder-ser, es constitutivo de lo real en cuanto que prescriptor del modo como ha de haber mundo. En esta relación con el poder-ser es que Heidegger puede afirmar, entonces: "El ser-el-ahí es lo que está siendo (Seiendes), al cual en su ser le va éste mismo [ser]" (2001, p. 191).

Tal expresión es la que parece sintetizar la primacía de la Existencialidad propia del cuidado. El cuidado, afirmamos, constituyente del mundo, no implica tan solo "futuro", en cuanto que "proyecto a un poder ser", sino que, en última instancia, señala a un tenerse a sí mismo en dicho proyecto. En efecto, en el contexto de un análisis gramatical de la expresión "irle" (es geht um), como lo hace Baur, es posible destacar este movimiento "hacia sî" propio del Dasein, haciendo énfasis en una cierta "circularidad en torno a sí mismo" (Baur, 2006, pp. 110 y ss.). Es decir, la temporalidad que es el "ser-el-ahî" anuncia una reflexión: una "autoapropiación" que actúa como horizonte último de articulación. Este es, en última instancia, el sentido fundamental del movimiento de aperturidad que el Dasein es: desde el cuidado, desde un "hacia sí mismo", que es el modo como el existir es, se abre un "para el existir", constituyente de la realidad diversa. A la realidad le pertenece, en su ser, el cuidado, pues el cuidado es un ocuparse en ser la posibilidad asumida a la manera fáctica de "otorgar-se" realidad.

Es por esta razón que se puede entender que el "irle" (es geht um) propio de la caracterización heideggeriana del Dasein no debe entenderse sino como una determinación esencial del modo como acaece la apertura del Ahí. El término expresa, por tanto, que al Dasein no le es indiferente el ente que él abre, sino todo lo contrario, pues la apertura se despliega en el horizonte de conseguirse como 
posibilidad. La aperturidad no puede entenderse, por lo mismo, como una mera proyección "centrífuga" de cosas, lanzadas hacia afuera y abandonadas a ser para sí mismas, pues la diversidad del ente es tal para el Dasein mismo: es, como veíamos, su asunto, y es que el horizonte de apertura se constituye siempre en su mundo. Así, cada particularidad que la realidad muestre, "aparece" y solo "puede aparecer" al interior de un existir ek-stático, como lo que le concierne. De ahí podemos entender que la constitución del aparecimiento del ente intramundano acaezca, en palabras de Heidegger, al modo de una apelación al propio Dasein, porque lo que éste abre y descubre siempre es al modo de lo que le apela, ya sea en los modos concretos de lo interesante, lo atrayente, lo que le repele, lo indiferente, etcétera. Dicha incumbencia es, así, el carácter auténtico de la aparición de la realidad diversa. Entre esta apelación del ente intramundano, el Dasein, entonces, vive. Sin dicha "apelación”, afirma Heidegger, éste "no podría existir" (1994b, p. 180). En fin: el "aspecto" primario del ente intramundano para el existir es la "incumbencia" o "apelación". Mediante estos términos se caracteriza la particularidad vital de los entes entre los cuales el Dasein habita, aquella con la que la vida se confrontaría diariamente.

De acuerdo con lo anterior, ya es posible advertir que el ente intramundano jamás es un "ser en sî", sino primariamente un "ser para...”. Fink ya destacaba este carácter del ente del mundo en los planteamientos de Heidegger. Justamente, éste realza como carácter del mundo lo que él mismo denomina "Ser-para-nosotros" (Für-unssein), realzando al mundo como un "estar abierto para el hombre", es decir, su "accesibilidad", su "carácter público" (cfr. Fink, 1990, p. 151). En este contexto, se entiende que la comparecencia cotidiana del ente ha de arraigarse en un "ahora", en una "situación vital" que la descubra en su concretud. El escritorio en el que se escribe no es un "absoluto", sino aquel que en una situación determinada de trabajo concreto se nos ofrece con tales o cuales cualidades, como podrían ser, por ejemplo, lo "suficiente" o "insuficiente" de su tamaño.

Mas, si la realidad abierta ha de fundarse en el "ser-el-ahí", nos preguntamos cómo esto ocurre. Según lo anterior, podríamos decir que sin una relación del existir con la posibilidad que él mismo es, aquello que éste descubra no le "apelaría" y, por ende, no habría 
presencia alguna. La "apelación" del ente intramundano solo puede articularse desde el modo como el Dasein se concierne a sí mismo respecto de la posibilidad que "ha de ser". En otras palabras: la aperturidad que es el "ser-el-ahî" no es un movimiento que esté originariamente proyectando mundo. El movimiento primario del existir, en cuanto articulador de mundo, no es "hacia lo otro", sino "hacia sí mismo": un proyecto a sí mismo como posibilidad es el que prescribe co-originariamente la articulación del mundo que contribuye o no a dicho poder-ser. Según lo anterior, se observa que la relación existencial propia del Dasein trasciende a su realidad diversa, para abrirla y descubrirla en cuanto que un movimiento "hacia sî", hacia la posibilidad que le constituye como un "sí mismo".

Comprendemos, así, el sentido existencial que implica pensar la constitución de lo real desde el fenómeno de la aperturidad. El cuidado pone de manifiesto que lo humano presenta en su propia esencia un carácter temporal que, desplegándose al modo de una autoapropiación, permite al ente ser lo que es. Justamente, en el contexto de este movimiento de auto-apropiación es que Heidegger reconoce la definición kantiana del tiempo como "auto-afección" (Selbstaffektion), entendiéndola como un "incumbir-se" (Selbstangang) propio del sujeto (cfr. 1995, p. 391), que posibilitaría el carácter de lo que le "está en contra" (Widerstand), constituyente de la "objetualidad" (Gegen-ständlichkeit), es decir, del modo como el ente se le "opone" (ofrece) al mismo. No obstante, se advierte la reformulación del sujeto kantiano, entendido ahora, por Heidegger, como un existente dirigido a un futuro: al poder-ser. Es en este sentido que Heidegger remitirá al cuidado (1995, pp. 396 y ss.). Dicha auto-afección o autoincumbirse es la que permite, por ende, al Dasein articular aquella accesibilidad para sí de todo aquello que él no es (cfr. Heinz, 1982, pp. 131 y ss.).

En definitiva, desde este movimiento a sí mismo es que podemos entender el carácter espacio-temporal del ente en esta dimensión eminentemente vital. Los "antes, acá", "ahora, allá", "después, ahî" que referíamos para destacar cómo es que el espacio y el tiempo delimitan la diversidad de la realidad, han de arraigarse en un ámbito existencial que los determina. Esta espacio-temporalidad constitutiva de la particularidad de cada ente no puede, por tanto, 
sino acaecer desde la auto-apropiación, pues desde ella es que estas nociones adquieren "concretud", en una situación vital determinada. Es decir, la espacio-temporalidad fáctica que otorga la particularidad al ente intramundano pertenece esencialmente a un "cuándo", a un instante. No puede haber un "antes", "ahora" o "después", un "acá" o un "allá" puros, abstractos, sino que han de emerger y configurarse en una situación vital específica, pues estos son en el existir que cuida de ser la posibilidad que ha resuelto ser. Así, la espacio-temporalidad que posibilita la diversidad de la realidad ha de entenderse desde la relación del "ser-el-ahî" consigo mismo, es decir, con su propio poder-ser. Este horizonte futuro, en consecuencia, se muestra como el fundamento de la particularidad del ente intramundano: lo real se funda, por tanto, en el tiempo.

Así, las presentes reflexiones parecen hacer explícito el derecho concreto con el que Heidegger puede afirmar: "Si no hay Dasein que exista, tampoco hay mundo alguno 'ahí'” (2001, p. 265). El movimiento del existir, que es el mismo acto de apertura, es, pues, el que posiciona un mundo en su instante vital. En dicha expresión se encuentra implícita la radicalidad del "irle en su propio ser" que caracteriza al Dasein, como el horizonte fundamental de la constitución de su realidad. El fenómeno del Dasein, esto es, de lo propiamente humano, se explicita como el acto de conformación de aquella realidad en la que vivimos, de aquello que en su diversidad concierne a la vida humana. Asimismo, se destaca la primacía del cuidado, es decir, del ser mismo de la aperturidad del mundo, en la constitución del ente en cuanto que nos incumbe. Con ello, se hace posible comprender, desde los planteamientos heideggerianos, cómo es que la "realidad", tal y como se nos ofrece, es, en estricto rigor, "asunto nuestro", a saber, porque lo humano abre y deja que se le presente aquello que le apela en el horizonte de la consecución de su posibilidad. Le es propio a lo humano, en definitiva, donarse una realidad que, en última instancia, comparte su propia naturaleza.

Así es como el conjunto de estas problemáticas podría ayudarnos a comprender cómo es que el planteamiento heideggeriano del ser humano como Dasein radicaría, en estricto rigor, en el problema de la constitución de nuestro mundo. El término "Dasein", decíamos, no refiere a un polo subjetivo que se comporta de tal o cual manera 
fáctica, ni con su entorno ni consigo mismo, sino que su pretensión es la de aprehender aquel acto de presentación originario de lo que a cada existente comparece y con lo que se ocupa. Por tanto, ya podemos entender que Dasein, en cuanto que aperturidad, más allá de reservarse para individuos particulares, ha de ser entendido en relación con aquel fenómeno que, a juicio de Heidegger (2001, p. 225), fue concebido originariamente por el pensar griego y fue expresado como alétheia, esto es: de-velamiento. Dasein es, discutíamos, hacer público al ente del mundo des-ocultándolo de su anonimidad para hacerlo comparecer al modo como ha de exhortarnos. No es casualidad, de hecho, que a la problemática heideggeriana del Dasein se integre el tradicional problema del lumen naturale (cfr. Heidegger, 2001, p. 133). Aquel que, como en detalle lo hace Strube, retrocede a la propia tradición metafísica, mas ahora reformulado como un acto del existir que consiste primariamente en dar luz al ente, entendiendo dicho fenómeno según las estructuras del ser-enel-mundo y finalmente, reparando en el cuidado (Sorge) (cfr. Strube, 1996, p. 111). El Dasein es en sí, podríamos decir desde las presentes reflexiones, el acto de iluminar, de des-velar al ente, desde su estructura esencial: un dejarse acaecer a sí mismo como la posibilidad que se ha resuelto ser. En definitiva, es precisamente la luz del Dasein la que en este trabajo ha estado en discusión, y que, como Heidegger señala, solo sería comprensible "si interrogamos la aprehensión del ser total del Dasein, el cuidado, según el fundamento unitario de su posibilidad existencial. La temporalidad ekstática ilumina el ahí originariamente" (2001, p. 351). Justamente, dicha tesis es la que en el presente trabajo se ha intentado pensar en concreto tomando como punto de partida el problema de la percepción sensible 


\section{Referencias}

Baur, P. (2006). Das "Es geht um". Das Es als philosophisches Problem im Rückgriff auf Heidegger und Hegel. Alea. Revista Internacional de Fenomenología y Hermenéutica, 4, 93-126.

Beaufret, J. (1993). Al encuentro de Heidegger. Caracas: Monte Ávila.

Brentano, F. (1976). Philosophische Untersuchungen zu Raum, Zeit und Kontinuum. Hamburg: Felix Meiner Verlag.

Cassirer, E. (1931). Kant und das Problem der Metaphysik. Bemerkungen zu Martin Heideggers Kant-Interpretation. Kant-Studien, 36, 1-26.

Courtine, J.-F. (1988). Le préconcept de la phénoménologie et de la problématique de la vérité dans Sein und Zeit. In F. Volpi (Ed.), Heidegger et l'idée de la phénoménologie (pp. 81-106). Dordrecht: Kluwer Academic Publishers.

Figal, G. (2007). Heidegger als Aristoteliker. In A. Denker, G. Figal, F. Volpi \& H. Zaborowski (Eds.), Heidegger-Jahrbuch 3: Heidegger und Aristoteles (pp. 53-76). Freiburg: Verlag Karl Alber.

Fink, E. (1990). Welt und Endlichkeit. Würzburg: Königshausen \& Neumann.

Fleischer, M. (1991). Die Zeitanalysen in Heideggers 'Sein und Zeit': Aporien, Probleme und ein Ausblick. Würzburg: Könnigshausen und Neumann.

Heidegger, M. (1964). Lettre à Jean Beaufret. In R. Munier (Ed.), Lettre sur l'humanisme. Paris: Aubier-Montaigne.

Heidegger, M. (1976). Brief über den "Humanismus". In F.-W. von Herrmann (Ed.), Wegmarken (pp. 313-364). Frankfurt am Main: Klostermann.

Heidegger, M. (1992). Platon: Sophistes. Frankfurt am Main: Klostermann.

Heidegger, M. (1994a). Prolegomena zur Geschichte des Zeitsbegriffs. Frankfurt am Main: Klostermann.

Heidegger, M. (1994b). Zollikoner Seminare. Protokolle-Zwiegespräche-Briefe. Frankfurt am Main: Klostermann.

Heidegger, M. (1995). Phänomenologische Interpretation von Kants Kritik der reinen Vernunft. Frankfurt am Main: Klostermann.

Heidegger, M. (1997). Die Grundprobleme der Phänomenologie. Frankfurt am Main: Klostermann.

Heidegger, M. (2001). Sein und Zeit. Tübingen: Max Niemeyer Verlag.

Heidegger, M. (2002). Grundbegriffe der aristotelischen Philosophie. Frankfurt am Main: Klostermann. 
Heinz, M. (1982). Zeitlichkeit und Temporeität. Würzburg: Königshausen \& Neumann.

Husserl, E. (1928). Vorlesungen zur Phänomenologie des inneren Zeitsbewusstseins. Halle: Niemeyer Verlag.

Johnson, F. (2012). La investigación acerca del otro y la filosofía existencial. En Actuel Marx 13 (pp. 45-69). Santiago de Chile: LOM Ediciones.

Kontos, P. (1996). D'une phénoménologie de la perception chez Heidegger. Dordrecht: Kluwer Academic Publishers.

Perrin, C. (2010). Lorigine et les fondements de la question cartésienne chez Heidegger. Studia Phaenomelogica, 10, 333-357.

Rockmore, T. (Ed.) (2000). Heidegger, german idealism $\mathcal{E}$ neo-kantianism. New York: Humanity Books.

Rodríguez, R. (2014). Percepción e interpretación. Heidegger y la tradición hermenéutica. En J. J. García Norro, R. Rodríguez García y M. J. Callejo Hernenz (Eds.), De la libertad del mundo. Homenaje a Juan Manuel Navarro Cordón (pp. 687-705). Madrid: Escolar / Mayo Editores.

Strube, C. (1996). Die existenzial-ontologische Bestimmung des lumen naturale. In Heidegger Studien: Thinking in the Crossing. Toward the arrival of 'Be-ing' (Vol. 12, pp. 109-119). Berlin: Duncker \& Humblot.

Strube, C. (Ed.) (2009). Heidegger und der Neukantismus. Würzburg: Königshausen \& Neumann.

Vigo, A. (1997). Temporalidad y trascendencia. La concepción heideggeriana de la trascendencia intencional en Sein und Zeit. Acta Philosophica, 6(1), 137-153.

Volpi, F. (2007). Heidegger und der Neoaristotelismus. In A. Denker, G. Figal, F. Volpi \& H. Zaborowski (Eds.), Heidegger-Jahrbuch: Heidegger und Aristoteles (Vol. 3, pp. 221-236). Freiburg: Verlag Karl Alber.

Volpi, F. (2012). Heidegger y Aristóteles. Buenos Aires: F. C. E. 